\title{
The analysis of fertility quality of life and the influencing factors of patients with repeated implantation failure
}

\author{
Ying $\mathrm{Ni}^{1}$, Chenye Tong ${ }^{1}$, Limin Huang ${ }^{1}$, Wenjie Zhou $^{2}$ and Aijun Zhang ${ }^{2^{*}}$ (B)
}

\begin{abstract}
Background: The objective of this study was to investigate the current status of fertility quality of life (QoL) and explore the influencing factors for infertile women with repeated implantation failure (RIF).

Methods: The sample consisted of 137 infertile women with RIF who were under treatment from January 2019 to December 2019 in the Reproductive Medical Center of Ruijin Hospital, affiliated with Shanghai Jiaotong University School of Medicine in China. A general information questionnaire, FertiQoL scale, perceived social support scale (PSSS), self-rating anxiety scale (SAS), and self-rating depression scale (SDS) were used to analyse the fertility QoL and related factors of RIF patients.
\end{abstract}

Results: The total fertility QoL score of RIF patients was $60.44 \pm 11.60$. The results of multivariate regression analysis showed that residence, financial difficulties, male infertility, BMI index, depression, and family social support were the main factors that influenced the fertility QoL of RIF patients (adjusted $R^{2}=0.762$ ).

Conclusion: Based on the results of this study, RIF patients' psychological status must be addressed. Corresponding interventions such as building a sound family and social support system, creating a good medical environment and offering diverse health education should be provided to improve the fertility QoL of RIF patients.

Keywords: Repeated implantation failure, Fertility quality of life, Social support, Anxiety, Depression, Influencing factors

\section{Background}

With changes in the living environment, the accelerating pace of life and delays in marriage and childbearing, the incidence of infertility is rising year by year. According to statistics from the World Health Organization (WHO), approximately $8-12 \%$ [1] of couples worldwide have experienced infertility. Since the approaches of controlled ovarian stimulation (COS) and the conditions of the embryonic laboratory have improved,

\footnotetext{
*Correspondence: elaineyao@163.com

${ }^{2}$ Reproductive Medical Center of Ruijin Hospital Affiliated to Shanghai

Jiaotong University School of Medicine, 197 Ruijin 2nd Road, Shanghai 200025, China

Full list of author information is available at the end of the article
}

in vitro fertilization-embryo transfer (IVF-ET), as the main assisted reproductive therapy for infertile patients, brings hope to many infertile patients. However, despite high-quality embryos, many patients remain whose embryos cannot be implanted normally for various reasons. Repeated implantation failure (RIF) refers to failure to conceive after three or more in vitro fertilization (IVF) cycles, intracytoplasmic sperm injection (ICSI) embryo transfer cycles, or frozen-thawed embryo transfer cycles or four or more high-quality embryo transplantation cycles [2]. The incidence of RIF reaches $5 \%-10 \%$ during IVF/ICSI-assisted pregnancy treatment [3].

Infertility is one of the greatest stressors in life and results in psychological distress [4]. It can lead to negative psychological consequences and diminished original author(s) and the source, provide a link to the Creative Commons licence, and indicate if changes were made. The images or other third party material in this article are included in the article's Creative Commons licence, unless indicated otherwise in a credit line to the material. If material is not included in the article's Creative Commons licence and your intended use is not permitted by statutory regulation or exceeds the permitted use, you will need to obtain permission directly from the copyright holder. To view a copy of this licence, visit http://creativecommons.org/licenses/by/4.0/. The Creative Commons Public Domain Dedication waiver (http://creativeco mmons.org/publicdomain/zero/1.0/) applies to the data made available in this article, unless otherwise stated in a credit line to the data. 
quality of life and well-being [5]. Studies have shown that a poor psychological state can reduce the pregnancy rate of IVF-ET and can have adverse effects on pregnancy outcome [6]. The QoL of women with infertility is obviously lower than that of other women of childbearing age [7]. The decrease in patients' QoL affects patient treatment compliance, thereby affecting the pregnancy rate [8]. Coughlan et al. [9] compared psychological stress among women with and without RIF and found that it was significantly higher among women with RIF. As repeated failure of infertility, RIF causes a heavy financial burden and mental stress on patients and families and affects their quality of life (QoL) [10].

Recent research shows that the influencing factors of the QoL of women with infertility mainly include age, gender, educational level, duration of infertility, fertility expectation, psychological status, marital relationship, and history of assisted pregnancy. According to Hassanin [11] and Karabulut et al. [12], women with secondary infertility and with higher education levels have higher fertility QoL, and the duration of infertility and desire for psychological support are negatively correlated with QoL. According to Chachamovich [13], low educational level, strong desire to have children, poor marriage relationship, history of assisted pregnancy and long duration of infertility reduce the QoL of women with infertility. Rashidi [14] showed that the duration of infertility or the attribution of infertility had no effect on health-related QoL in infertile patients.

QoL is also one of the main indexes to assess the effects of medical and nursing work. It has become one of the standards of nursing to include a QoL assessment in the clinical treatment of infertility problems [15]. However, to the best of our knowledge, there is little research focused on the QoL specifically in case of RIF patients. The purpose of this study was to investigate the current status of the fertility QoL of RIF patients and to discuss the influencing factors on their fertility QoL, thereby providing a scientific basis for effective clinical interventional measures and helping to improve the fertility QoL of RIF patients.

\section{Methods}

\section{Ethics statement}

The study protocol was in accordance with the ethical standards and was approved by the Ethics Committee of Shanghai Ruijin Hospital. Written informed consent was obtained from each participant. Information collected from all participants was kept confidential and anonymous.

\section{Data and study design}

This study was conducted among outpatient women diagnosed with infertility with RIF from January to December 2019. All participants were recruited at the Center of Reproductive Clinic, Ruijin Hospital, Shanghai Jiaotong University School of Medicine in China. The inclusion criteria were as follows: (1) women outpatients diagnosed with RIF, which is defined by Coughlan [2] and others as $\geq 3$ cycles, $\geq 4$ high-quality embryos, age $<40$ years old; (2) women who signed informed consent after completely comprehending the contents of the study; (3) women who had basic ability to read, communicate, and complete the questionnaire independently. The exclusion criteria were as follows: (1) women diagnosed with previous or current mental disorders, cognitive impairment, or inability to understand the content of the questionnaire; (2) women diagnosed with severe chronic diseases; (3) women who had recently undergone major domestic affairs.

After written informed consent was obtained for this study, a self-reported questionnaire was distributed to each eligible participant, and clinical data were collected from their medical records. Questionnaires with any missing data were excluded from statistical analyses. All questionnaires were required to be completed independently by the patients. The questionnaires were collected, and their completeness was checked on the spot. The investigation process was conducted anonymously. The questionnaire elimination criteria were as follows: (1) the same answer for each question or (2) withdrawal from this research for various reasons. A total of 150 questionnaires were sent out and all of them were received, for a response rate of $100 \%$. Thirteen questionnaires were excluded due to missing answers, the same answers for each question, or deviation from the inclusion criteria. In total, 137 complete responses were received in the present study. The effective rate of the questionnaires was 91.33\%.

\section{Measures}

\section{Demographic characteristics}

The demographic characteristics were collected with a general information questionnaire designed by our panel, which included age, height, weight, residence, occupation, education level, monthly household income, attribution of infertility, types of infertility, years of infertility, and number of treatment cycles.

\section{Measurement of fertility QoL}

The simplified Chinese version of the FertiQoL Scale was used to measure fertility QoL in women with infertility with RIF in this study. The FertiQoL Scale was designed by experts from the European Society of Human 
Reproduction and Embryology and the American Society of Reproductive Medicine [16]. It is used to measure the fertility QoL of infertile patients during the treatment period. The scale has been translated into more than 20 languages. It is widely used among infertile patients in different countries and regions of the world and has good reliability, validity, and sensitivity $[17,18]$. The scale is divided into two parts: a core module and an optional treatment module. There are 36 items in total, including 2 independent items of subjective general health status and subjective overall QoL and 24 core items including affective responses, physical and mental relationships, marital relationships, and social relationships. The 10 optional treatment items include treatment tolerance and treatment environment. The FertiQoL Scale is scored with 5 grades; each item is scored from 0 to 4 . Of these, 7 items are reverse scored. The original score is calculated by adding the scores of each item, which is standardized to a 100-point system. The standard score is calculated as follows: original total score *25/the number of items[16]. In the present study, the Cronbach's alpha coefficient of the FertiQoL Scale was 0.921.

\section{Measurement of social support}

The Chinese version of the Perceived Social Support Scale (PSSS), designed by Zimet et al. [19] in 1988, was used to assess social support. The PSSS is a social support scale that emphasizes individual self-understanding and feelings. It measures the degree of social support perceived by the individual, such as from family, friends and others. The total score reflects the overall level of social support perceived by the individual. The scale consists of 12 self-rating items, including 3 subscales: family support, friend support, and other support (teachers, classmates, relatives). Each item is scored from 1 to 7 , with "Strongly disagree" as 1 point and "Strongly agree" as 7 points. The total score is $12-84$. The higher the score of each dimension and the overall level, the higher the level of social support: 12-36 points indicate low support. 37-60 points indicate intermediate support, and 61-84 points indicate high support. The scale is widely used in various fields and has been proven to have good reliability and validity. The Cronbach's alpha coefficient of the PSSS was 0.941 in this study.

\section{Measurement of anxiety}

The Self-rating Anxiety Scale (SAS), developed by Zung [20] in 1971, is used to measure the degree of anxiety in adults. In this study, the infertility-related anxiety of participants was measured with the Chinese version of the SAS. The SAS has 20 items, each of which has a 4-level score: "1"=no or seldom; "2"= sometimes; "3"= most of the time; and "4" = most or all of the time. Five items are scored inversely. The score of each item is added for the initial score and then multiplied by 1.25 to obtain the standard score. Mild anxiety is indicated by a standard score of 50-59 points, moderate anxiety is indicated by a standard score of 60-69 points, and severe anxiety is indicated by more than 70 points. The Cronbach's alpha coefficient of the SAS was 0.897 in this study.

\section{Measurement of depression}

The Self-rating Depression Scale (SDS), developed by Zung [21] in 1965, is used to measure the severity of depression in adults. We used the Chinese version of the SDS to measure the infertility-related depression of participants in this study. The SDS has 20 items, each of which is assessed in 4 grades based on the following criteria: "1"= no or seldom; "2"= sometimes; "3"= most of the time; and "4" = most or all of the time. Ten items are scored inversely. At the end of the assessment, the scores of the 20 items are added for the initial score and then multiplied by 1.25 to obtain the standard score. Mild depression is indicated by a standard score of 50-59 points, moderate depression is indicated by a standard score of 60-69 points, and severe depression is indicated by more than 70 points. The Cronbach's alpha coefficient of the SDS was 0.885 in this study.

\section{Statistical analysis}

In this study, statistical analysis was performed with SPSS 23.0 software. The measurement data are presented as the mean \pm standard deviation, and the enumeration data are expressed as the frequency and constituent ratio (\%). The difference in the demographic and disease characteristic variables of the FertiQol was tested by an independent-sample t-test and single-factor variance analysis. Fertility QoL, social support, anxiety, and depression were analysed by Pearson correlation analysis. The influencing factors of fertility QoL were analysed by multiple linear regression analysis. $\mathrm{P}<0.05$ was considered statistically significant.

\section{Results \\ Description of the participants and fertility QoL}

The ages of the 137 patients ranged from 26 to 39 years old, with an average age of $32.80 \pm 3.63$ years. BMI (body mass index) was $17.36-33.95 \mathrm{~kg} / \mathrm{m}^{2}$, with an average BMI of $21.95 \pm 3.08 \mathrm{~kg} / \mathrm{m}^{2}$. The average infertility period was $5.39 \pm 2.87$ years, ranging from 1 to 14 years. The number of treatment cycles was 3-6, and the average number of treatment cycles was $2.01 \pm 0.84$.

The total fertility QoL score of RIF patients was $60.44 \pm 11.60$ points. The score of the core module was $59.80 \pm 13.90$. The score of the treatment module was $61.99 \pm 10.65$. The dimensions were arranged according 
to the score from high to low: treatment environment, social relationship, marriage relationship, emotional reaction, treatment tolerance, and physical and mental relationships. Details are presented in Table 1.

\section{Social support, anxiety and depression}

The social support score of RIF patients in this study was $60.92 \pm 12.02$ points. The scores for family support, friend support and other support were $21.31 \pm 5.01$, $19.78 \pm 4.60$ and $19.83 \pm 4.03$, respectively. The anxiety score was $54.84 \pm 9.79$, and the depression score was $58.22 \pm 9.99$. Ninety-five out of 137 RIF patients had an anxiety state that was $69.34 \%$ of the incidence rate and $57.13 \pm 9.08 \%$ of the fertility QoL score. There were 114 patients with depression. The incidence rate was $83.21 \%$, and the fertility QoL score was $58.18 \pm 8.68$. Anxiety and depression status are detailed in Table 2.

\section{Univariate analysis of fertility QoL}

The total scores for the fertility QoL of RIF patients differed in the following factors: BMI segment, educational level, residence, years of infertility, employment status, monthly household income, self-assessment of financial difficulties, purpose of assisted pregnancy, attribution of infertility, and number of treatment cycles $(\mathrm{P}<0.05)$.

Table 1 Total Fertility QoL Score and Each Dimension Score of RIF Patients $(n=137)$

\begin{tabular}{lcc}
\hline Item & Entries & Score $(\mathbf{x} \pm \mathbf{s})$ \\
\hline Therapeutic environment & 6 & $66.88 \pm 11.72$ \\
Social relations & 6 & $64.78 \pm 18.13$ \\
Marital relations & 6 & $63.96 \pm 12.53$ \\
Emotional response & 6 & $56.17 \pm 17.05$ \\
Treatment tolerability & 4 & $54.65 \pm 15.51$ \\
Relationship between body and mind & 6 & $54.29 \pm 17.96$ \\
Total Score of Core Module & 24 & $59.80 \pm 13.90$ \\
Total Score of Treatment Module & 10 & $61.99 \pm 10.65$ \\
Total Score of Fertility QoL & 34 & $60.44 \pm 11.60$ \\
\hline
\end{tabular}

Multivariate linear regression analysis on the influencing factors

The fertility QoL score was regarded as a dependent variable, and the variables with statistical significance in univariate analysis were included in the regression model. As shown in Table 5, the results of multivariate regression analysis showed that residence, financial difficulties, male infertility, BMI index, depression, and family social support were the main factors that influenced the fertility QoL of RIF patients (adjusted $\mathrm{R}^{2}=0.762$ ).

\section{Discussion}

\section{Current status of fertility QoL in RIF patients}

Karabulut et al. [22] used the FertiQoL scale to study the fertility QoL of women with IVF. The results showed that the average fertility QoL score of women with infertility was 66. This study used the FertiQoL scale to investigate RIF patients in our centre. The average fertility QoL score was $60.44 \pm 11.60$, and the average score range of each dimension was 54.29-66.88. Compared with the Karabulut study, the fertility QoL and scores of each dimension of RIF patients in this study were reduced to varying degrees. Ying L Y et al. [23] reported that the fertility QoL is significantly lower than that of women of childbearing age without infertility. Factors including the specific Chinese cultural background, traditional concepts, heavy financial burden and social public opinion lead to low QoL on infertile women. RIF patients, as part of infertile women, may suffer more economic pressure, physical pain, psychological distress, and disappointment caused by repeated failure during treatment.

In this study, among the dimensions of fertility QoL, the scores of physical-mental relationship and treatment tolerance were lower in RIF patients. The longterm, complicated treatment process, continuous drug use, surgical treatment and other invasive treatments cause physical pain, financial pressure, and psychological shock to RIF patients, which result in a sharp decline of their QoL. In addition, RIF patients are under pressure from their spouses and family members. As couples are daunted by repeated treatment failure, their emotional communication worsens; the resultant marriage crisis may cause them to fail to obtain sufficient family and social support, which damages the fertility

Table 2 Anxiety and Depression Status $(n=137)$ and Fertility QoL Score of RIF Patients

\begin{tabular}{|c|c|c|c|c|c|c|}
\hline & $\begin{array}{l}\text { Total score } \\
x \pm s\end{array}$ & Number $\mathbf{n}$ & Incidence \% & $\begin{array}{l}\text { Mild } \\
\%\end{array}$ & Moderate-severe \% & Fertility QoL score $x \pm s$ \\
\hline Anxiety & $54.84 \pm 9.79$ & 95 & $\begin{array}{l}69.34 \\
(95 / 137)\end{array}$ & $\begin{array}{l}33.58 \\
(46 / 137)\end{array}$ & $\begin{array}{l}35.77 \\
(49 / 137)\end{array}$ & $57.13 \pm 9.08$ \\
\hline Depression & $58.22 \pm 9.99$ & 114 & $\begin{array}{l}83.21 \\
(114 / 137)\end{array}$ & $\begin{array}{l}36.50 \\
(50 / 137)\end{array}$ & $\begin{array}{l}46.72 \\
(64 / 137)\end{array}$ & $58.18 \pm 8.68$ \\
\hline
\end{tabular}


QoL. Among the dimensions, the treatment environment ranked the highest. By optimizing the treatment environment and process, formulating a proper set of treatment and nursing measures, increasing patients' trust in medical institutions and professionals and reducing the negative emotions and psychological pressure of RIF patients, we can enhance the therapeutic effects and improve their fertility QoL.

\section{Analysis of influencing factors of fertility QoL}

\section{Residence}

This study found that RIF patients in urban areas exhibit higher fertility QoL than patients in rural areas (Table 3). Patients in rural areas maintain relatively old-fashioned ideas and are more influenced by the traditional Chinese saying, "There are three forms of unfilial conduct, of which the worst is to have no descendants". In China's

Table 3 Univariate Analysis of Influencing Factors of Fertility QoL of RIF Patients $(x \pm s)$

\begin{tabular}{|c|c|c|c|c|c|}
\hline \multirow[t]{2}{*}{ Variables } & \multirow[t]{2}{*}{ Group } & \multirow[t]{2}{*}{ Proportion $\%$} & \multicolumn{3}{|c|}{ Total Score of Fertility QoL } \\
\hline & & & Score & $t / F$ & $P$ \\
\hline \multirow[t]{3}{*}{ Age (years) } & $\leq 30$ & $42(30.66 \%)$ & $58.84 \pm 10.37$ & 1.583 & 0.209 \\
\hline & $31-35$ & $56(40.88 \%)$ & $59.76 \pm 12.19$ & & \\
\hline & $36-40$ & $39(28.47 \%)$ & $63.16 \pm 11.81$ & & \\
\hline \multirow[t]{3}{*}{ BMl index } & $<18.5$ & $6(4.38 \%)$ & $41.30 \pm 9.89$ & 10.147 & 0.000 \\
\hline & $18.5-23.9$ & 108 (78.83\%) & $60.91 \pm 11.06$ & & \\
\hline & $\geq 24$ & $23(16.79 \%)$ & $53.27 \pm 11.60$ & & \\
\hline \multirow[t]{4}{*}{ Educational level } & Junior high school or below & $25(18.25 \%)$ & $56.24 \pm 13.25$ & & \\
\hline & $\begin{array}{l}\text { Senior high school/Technical sec- } \\
\text { ondary school }\end{array}$ & $17(12.41 \%)$ & $65.23 \pm 10.96$ & 8.913 & 0.000 \\
\hline & Junior College/Undergraduate & $83(60.58 \%)$ & $59.71 \pm 11.31$ & & \\
\hline & Master's degree or above & $12(8.76 \%)$ & $67.53 \pm 4.29$ & & \\
\hline \multirow[t]{3}{*}{ Residence } & City & $76(55.47 \%)$ & $61.19 \pm 12.63$ & 3.970 & 0.025 \\
\hline & Town & $43(31.39 \%)$ & $61.66 \pm 9.79$ & & \\
\hline & Rural & $18(13.14 \%)$ & $54.41 \pm 9.54$ & & \\
\hline \multirow[t]{3}{*}{ Years of infertility (years) } & $\leq 3$ & $36(26.28 \%)$ & $67.46 \pm 8.50$ & 13.703 & 0.000 \\
\hline & $4-5$ & $44(32.12 \%)$ & $57.15 \pm 11.46$ & & \\
\hline & $\geq 6$ & $57(41.61 \%)$ & $58.55 \pm 11.70$ & & \\
\hline \multirow[t]{2}{*}{ Employment status } & Rest & $51(37.23 \%)$ & $56.00 \pm 11.74$ & 0.642 & 0.000 \\
\hline & On-the-job & $86(62.77 \%)$ & $63.08 \pm 10.73$ & & \\
\hline \multirow[t]{2}{*}{ Time-off or not } & No & $59(43.07 \%)$ & $60.92 \pm 13.34$ & 8.384 & 0.692 \\
\hline & Yes & $78(56.93 \%)$ & $60.09 \pm 10.16$ & & \\
\hline \multirow[t]{3}{*}{ Family monthly income } & $\leq 10,000$ & $69(50.36 \%)$ & $54.24 \pm 8.54$ & 42.215 & 0.000 \\
\hline & $10,001-15,000$ & $38(27.74 \%)$ & $62.27 \pm 10.86$ & & \\
\hline & $>15,000$ & $30(21.90 \%)$ & $72.40 \pm 8.10$ & & \\
\hline \multirow[t]{3}{*}{ Self-assessment of financial difficulties } & No difficulties & $38(27.74 \%)$ & $71.01 \pm 7.91$ & 58.216 & 0.000 \\
\hline & Slight difficulties & $70(51.09 \%)$ & $59.71 \pm 9.04$ & & \\
\hline & Very difficult & $29(21.17 \%)$ & $48.38 \pm 8.10$ & & \\
\hline \multirow[t]{2}{*}{ Purpose of assisted pregnancy } & Cephalic foetus & $124(90.51 \%)$ & $59.37 \pm 11.30$ & 0.734 & 0.001 \\
\hline & Second foetus & $13(9.49 \%)$ & $70.70 \pm 9.43$ & & \\
\hline \multirow[t]{2}{*}{ Type of infertility } & Primary infertility & $76(55.47 \%)$ & $59.39 \pm 12.37$ & 4.100 & 0.226 \\
\hline & Secondary infertility & $61(44.53 \%)$ & $61.77 \pm 10.50$ & & \\
\hline \multirow[t]{3}{*}{ Attribution of infertility } & Female factors & $72(52.55 \%)$ & $58.12 \pm 12.69$ & 3.251 & 0.046 \\
\hline & Male factor & $20(14.60 \%)$ & $62.98 \pm 8.28$ & & \\
\hline & Bilateral factors & $45(32.85 \%)$ & $63.04 \pm 10.38$ & & \\
\hline \multirow[t]{3}{*}{ Number of treatment cycles } & 3 & $47(34.31 \%)$ & $63.77 \pm 8.91$ & 16.322 & 0.000 \\
\hline & 4 & $41(29.93 \%)$ & $64.94 \pm 11.55$ & & \\
\hline & $\geq 5$ & $49(35.77 \%)$ & $53.50 \pm 10.80$ & & \\
\hline
\end{tabular}

Note: * indicates $\mathrm{P}<0.05$ 
rural areas, children are the link to family. It is an important task for most rural families to have a child and carry on the family line. They tend to attribute infertility to women and place a greater mental burden on infertile women with RIF, whose QoL is consequently severely impaired. Moreover, rural patients with RIF must travel to urban areas far from home for examinations and treatments, which causes them hardships, such as additional transportation and accommodation costs. In contrast, despite the rapid pace of life, high pressure and irregular routine, women in urban cities are relatively more independent and well paid and generally have a later childbearing age. Furthermore, urban society is more tolerant and open to women with infertility. All of these factors may be responsible for the high fertility QoL scores in urban RIF patients.

\section{Attribution of infertility}

Infertility is often considered to be a decrease or loss of fertility. Therefore, patients with male infertility may suspect their masculinity, especially men with sexual dysfunction or azoospermia who may have strong feelings of inferiority and guilt [24]. This study found that male infertility is one of the factors that affects the QoL of infertile women with RIF (Table 5). It is likely that the negative emotions and personality changes related to male infertility lead to a lack of timely support, encouragement and comfort to RIF patients. Due to the lack of care from their husbands, the fertility QoL of women with RIF is low. As health care professionals, we should evaluate couples systematically to fully understand their emotional states. In addition, joint treatment and positive intervention for the couple are necessary to solve couples' psychological problems and improve the state of communication in couples. The ultimate goal is to enhance the marriage satisfaction of the couple. On the one hand, men are encouraged to support and accompany their wives. On the other hand, the couple should fully understand that reproduction is the responsibility of both parties, which requires mutual understanding and support as well as joint efforts.

\section{Financial difficulties}

Chachamovich et al. [25] reviewed the literature published in 1980-2009 on the factors that influence the QoL of patients with infertility and found that low income of women with infertility is a predictor of lower QoL. Keramat et al. [26] used the World Health Organization Quality of Life Brief (WHOQoL-BREF) and FertiQol to investigate 385 infertile couples and found that body section of the WHOQoL-BREF was significantly correlated with economic income. In the emotion/body part of the FertiQol subscale, the low-income group scored 49.82 points while the high-income group scored 56.08 points, with significant differences. In this study, monthly household income and financial difficulties were influencing factors of QoL (Table 5), which was consistent with the results of Chachamovich and other studies. The lower the family income, the lower the fertility QoL score. Moreover, there is a significant difference in the QOL scores of patients with high or low monthly family income (Table 3). In addition, failures in repeated implanting and enormous medical expenses exacerbate the financial burden, resulting in a decrease in QoL. Patients with low income must consider the basic needs of the family before the cost of assisted reproductive treatment, which affects QoL, while patients with high income can obtain more medical resources and receive better treatment. For families with financial difficulties, medical institutions can seek charity sponsorship and other means to realize patients' dreams of assisted pregnancy, thereby improving the QoL of these patients.

\section{BMI Index}

The body mass index (BMI) is a relative reference standard recommended by the WHO to assess the weight status of the body and is one of the important indicators for evaluating the fertility of women of childbearing age. Some scholars believe that overweight and obesity affect the quality of embryos and lead to many problems in the process of in vitro fertilization, such as high gonadotropin consumption, a decreased number of ova, a lower rate of high-quality embryos and clinical pregnancy, and an increased rate of abortion [27-29]. However, other researchers believe that overweight and obesity have no negative impact on the outcome of in vitro fertilizationembryo transfer therapy and do not affect the pregnancy outcome of in vitro fertilization [30,31]. The results from our study revealed that RIF patients with a BMI $\geq 24 \mathrm{~kg} /$ $\mathrm{m}^{2}$ had lower QoL scores than those with a BMI in the normal range of $18.5-23.9 \mathrm{~kg} / \mathrm{m}^{2}$ (Table 3). Similar to the study of Nanette Santoro, who compared 733 patients with polycystic ovary infertility and 865 patients with unexplained infertility [32], the higher the BMI of women with polycystic ovary is, the lower their fertility QoL scores are. It has been found that overweight is an important factor in anxiety and depression [33, 34], which is caused not only by external appearance characteristics but also by pathological changes. These patients exhibit abnormal emotions and behaviours due to altered hormone levels and neurotransmitter conduction in the body.

\section{Depression and anxiety}

The diagnosis and treatment of infertility can cause emotional and psychological stress in patients, of which 
Table 4 Correlation Analysis of Social Support, Anxiety, Depression and Fertility QoL in RIF Patients

\begin{tabular}{|c|c|c|c|c|c|c|c|}
\hline Variables & $\begin{array}{l}\text { Total Score } \\
\text { of fertility } \\
\text { QoL }\end{array}$ & Emotional response & $\begin{array}{l}\text { Relationship } \\
\text { between body } \\
\text { and mind }\end{array}$ & Marital relations & Social relations & $\begin{array}{l}\text { Therapeutic } \\
\text { environment }\end{array}$ & $\begin{array}{l}\text { Treatment } \\
\text { tolerability }\end{array}$ \\
\hline PSSS-Social support & $0.768^{* *}$ & $0.623^{* *}$ & $0.601^{* *}$ & $0.573^{* *}$ & $0.782^{* *}$ & $0.362^{* *}$ & $0.334^{* *}$ \\
\hline Family support & $0.745^{* *}$ & $0.537^{* *}$ & $0.652^{* *}$ & $0.528^{* *}$ & $0.732^{* *}$ & $0.434^{* *}$ & $0.306^{* *}$ \\
\hline Friend Support & $0.649^{* *}$ & $0.608^{* *}$ & $0.528^{* *}$ & $0.454^{* *}$ & $0.678^{* *}$ & $0.187^{*}$ & $0.254^{* *}$ \\
\hline Other support & $0.623^{* *}$ & $0.496^{* *}$ & $0.381^{* *}$ & $0.535^{* *}$ & $0.650^{* *}$ & $0.326^{* *}$ & $0.326^{* *}$ \\
\hline SAS-Anxiety & $-0.503^{* *}$ & $-0.430^{* *}$ & $-0.358^{* *}$ & $-0.436^{* *}$ & $-0.488^{* *}$ & $-0.203^{* *}$ & $-0.255^{* *}$ \\
\hline SDS-Depression & $-0.548^{* *}$ & $-0.528^{* *}$ & $-0.400^{* *}$ & $-0.475^{* *}$ & $-0.572^{* *}$ & $-0.093^{* *}$ & $-0.235^{* *}$ \\
\hline
\end{tabular}

Note: $1,{ }^{*}$ indicates $\mathrm{P}<0.01$, *indicates $\mathrm{P}<0.05$

$2,0.8-1.0$ very strong correlation, $0.6-0.8$ strong correlation, $0.4-0.6$ moderate correlation, $0.2-0.4$ weak correlation, $0.0-0.2$ very weak correlation

Table 5 Multivariate Linear Regression Analysis of Influencing Factors of Fertility QoL of RIF Patients

\begin{tabular}{|c|c|c|c|c|c|c|}
\hline Total Score of fertility QoL & $\begin{array}{l}\text { Partial regression } \\
\text { coefficient } \\
\text { B }\end{array}$ & $\begin{array}{l}\text { Standardized } \\
\text { coefficient } \\
\text { Beta }\end{array}$ & t-value & $p$ value & Tolerance & VIF \\
\hline (Constant) & 55.267 & & 9.776 & 0.000 & & \\
\hline Residence $=$ City & -3.136 & -0.135 & -2.908 & 0.004 & 0.815 & 1.227 \\
\hline Self-Rating of financial difficulty $=$ relative difficulty & -4.473 & -0.193 & -3.327 & 0.001 & 0.518 & 1.929 \\
\hline Self-rated financial difficulties = great difficulty & -10.655 & -0.377 & -5.829 & 0.000 & 0.420 & 2.381 \\
\hline Attribution of infertility $=$ male factor & -2.994 & -0.091 & -2.052 & 0.042 & 0.882 & 1.133 \\
\hline BMl index classification $=<18.5$ & -8.011 & -0.142 & -3.027 & 0.003 & 0.798 & 1.253 \\
\hline BMI index classification $=\geq 24$ & 2.822 & 0.091 & 2.066 & 0.041 & 0.898 & 1.113 \\
\hline Total score of family support & 0.907 & 0.392 & 6.845 & 0.000 & 0.535 & 1.869 \\
\hline Standard score of depression & -0.279 & -0.240 & -4.611 & 0.000 & 0.647 & 1.546 \\
\hline Total score of other support & 0.438 & 0.152 & 2.724 & 0.007 & 0.564 & 1.774 \\
\hline
\end{tabular}

Note: $\mathrm{R}^{2}=0.777$, adjusted $\mathrm{R}^{2}=0.762, \mathrm{~F}=49.253, \mathrm{P}=0.000$. The regression model is established

anxiety and depression are the most common mental disorders [35]. Aarts et al. [36] used the HADS and FertiQol to study 472 infertile women in the Netherlands. They found that the quality of life of the patients was low, and there was a negative correlation between anxiety and depression with quality of life. Kahyaoglu et al. [37] conducted a cross-sectional study of 85 infertile women with FertiQol and HADS and found that the quality of life of patients with anxiety and depression scores over 8 was significantly impaired. A study by Wishmann et al. [38] showed that the self-esteem of women with infertility decreased significantly, which led to a decrease in their sexual quality of life. Their overall quality of life was also significantly affected. In this study, the anxiety score was $54.84 \pm 9.79$ and the incidence was $69.34 \%$, and the depression score was $58.22 \pm 9.99$, and the incidence was 83.21\% (Table 2), indicating that the psychological state of RIF patients is not optimistic; furthermore, the findings of our study are worse than those of Lakatos et al. (anxiety rate 39.6\%/depression rate 44.8\%) [39]. The scores for the fertility QoL of RIF patients with anxiety and depression were significantly lower $(57.13 \pm 9.08$ and $58.18 \pm 8.68$, respectively) (Table 2 ). We hypothesize that in China, the traditional ideology and societal gender orientation cause infertile women with RIF to experience pressure from family housework and working tasks, which increases their psychological and mental burden and seriously affects their fertility QoL. It has been reported in the literature [40] that during IVF-ET assisted pregnancy treatment, positive psychological support and counselling can effectively alleviate or eliminate psychological problems such as anxiety and depression, thus improving the health and QoL of patients with infertility and enhancing the treatment effects of infertility. It is suggested that when developing clinical technology, medical institutions should strengthen psychological counselling to provide RIF patients with appropriate opportunities to vent and alleviate their negative emotions. Similarly, health care professionals should strengthen health education, provide details of precautions and success rates during assisted pregnancy periods, and share successful cases of assisted pregnancy, thereby enhancing RIF 
patients' confidence in assisted pregnancy and reducing their psychological distress. Furthermore, for medical centres with sufficient resources to effectively address psychological problems and improve the fertility QoL of RIF patients, psychological counselling clinics, hotlines, public WeChat, QQ groups, WeChat groups and other platforms can be established to help patients understand fertility and medical information.

\section{Family support}

Martins et al. [41] investigated 252 infertile women under treatment and found that perceived family support directly or indirectly affected all aspects of stress related to fertility. The research of Yazdani et al. [42] showed that the quality of the relationship with their husband affects the marital satisfaction and marital quality of infertile women. This finding suggests that understanding and care from family members, the most intimate contact persons for patients, can help patients actively accept treatment, enhance their confidence to overcome the disease, improve their quality of life and promote rehabilitation. In this study, the total score of the social support scale was $60.92 \pm 12.02$, and the scores for family support and social support were most closely correlated with the scores of fertility QoL (Table 4) with a positive correlation $(R=0.745, R=0.768)$. This finding indicates that the more family support and social support that patients experience, the better their fertility QoL. According to the results of multivariate regression analysis (Table 5), the standardized coefficient beta of family support was the highest, suggesting that family support had the greatest impact on fertility QoL. A study by Ching-Yu Cheng et al. noted that the relationship between infertile women and their spouses and family members can have a positive or negative impact on women's psychological stress and QoL during assisted pregnancy treatment [43]. Takaki and Hibino et al. also noted in their research in 2014 that a lack of family support can create stressful situations and increase psychological pressure on infertile women [44]. Sufficient family support can enable patients to obtain more care and emotional support and can improve their QoL and their ability to deal with psychological stress. Therefore, for infertile women undergoing assisted reproductive therapies, health care professionals should (1) comprehensively evaluate family function, (2) help to establish a better family support system, (3) encourage family members to participate actively in various health education activities, (4) create a good family atmosphere, and (5) give patients more support and care to improve the patient's fertility QoL. It is also recommended that reproductive clinics can distribute missionary handbooks or play educational videos about assisted pregnancy and encourage couples to watch them together and discuss their feelings to reach mutual understanding and joint efforts in infertility treatment and the enhancement of family support, thereby improving their QoL and pregnancy rate.

\section{Limitations}

In this study, we mainly focused on the external influencing factors of the fertility QoL of infertile women with RIF. However, some internal positive factors, such as resilience, may also affect the fertility QoL of RIF patients. This area of research and clinical implications deserves to be further explored. What's more, further studies need to be conducted to examine whether the results of the present study are suitable to the different cultural context.

\section{Conclusion}

This study found that the fertility QoL of infertile women with RIF was closely related to residence, male infertility, financial difficulties, BMI, depression, and family social support. As medical practitioners, we should understand patients' positions and demands to achieve empathy. Moreover, it is necessary to create a good medical environment, respect the privacy of patients, and encourage patients to distract themselves to relieve their feelings. Finally, it is necessary to help patients establish a sound family and social support system. Through diverse types of health education, we can deepen patients' and their family members' understanding of infertility and encourage them to actively cooperate during treatment, thereby improving the therapeutic effects and the fertility QoL of patients.

\section{Abbreviations}

RIF: Repeated implantation failure; FertiQoL: Fertility quality of life; QoL: Quality of life; SD: Standard deviation; PSSS: Perceived Social Support Scale; SAS: Selfrating Anxiety Scale; SDS: Self-rating Depression Scale; COS: Controlled ovarian stimulation; IVF-ET: In vitro fertilization-embryo transfer; IVF: In vitro fertilization; ICSI: Intracytoplasmic sperm injection; BMI: Body mass index.

\section{Acknowledgements}

The authors would like to thank all the participants who voluntarily participated in this study and research assistants who performed the data collection.

\section{Authors' contributions}

NY made the contributions on study design, data collection, analysis, interpretation, and wrote the paper. ZAJ provided guidance in the study design, and is the corresponding author. TCY made contributions on investigation execution and data analysis. HLM assisted with the data interpretation. ZWJ reviewed the article for intellectual content. All authors have read and approved the final version of the manuscript.

\section{Funding \\ None.}

\section{Availability of data and materials}

The datasets used and/or analysed during the current study are available from the corresponding author on reasonable request. 


\section{Ethics approval and consent to participate}

All patients provided their informed written consent. The study was approved by the Ethics Committee of Shanghai Ruijin Hospital and was conducted in accordance with the principles of the Declaration of Helsinki.

\section{Consent for publication}

Not applicable.

\section{Competing interests}

The authors declare that they have no competing interests.

\begin{abstract}
Author details
${ }^{1}$ Nursing Department of Ruijin Hospital Affiliated to Shanghai Jiaotong University School of Medicine, 197 Ruijin 2nd Road, Shanghai 200025, China. ${ }^{2}$ Reproductive Medical Center of Ruijin Hospital Affiliated to Shanghai Jiaotong University School of Medicine, 197 Ruijin 2nd Road, Shanghai 200025, China.
\end{abstract}

Received: 28 August 2020 Accepted: 1 January 2021

Published online: 25 January 2021

\section{References}

1. Schmidt L, Holstein B, Christensen U, et al. Does infertility cause marital benefit? An epidemiological study of 2250 women and men in fertility treatment. Patient Educ Couns. 2005;59(3):244-51.

2. Coughlan C, Ledger W, Wang Q, et al. Recurrent implantation failure: definition and management. Reprod Biomed Online. 2014;28(1):14-38.

3. Mak J, chung C, chung J, , et al. The effect of endometrial scratch on natural-cycle cryopreserved embryo transfer outcomes: a randomized controlled study. Reprod Biomed Online. 2017;35(1):28-36.

4. Omani-Samani R, Ghaheri A, Navid B, Sepidarkish M, Maroufizadeh S. Prevalence of generalized anxiety disorder and its related factors among infertile patients in Iran: a cross-sectional study. Health Qual Life Outcomes. 2018;16(1):129.

5. Zurlo M, Volta D, Vallone F. Predictors of quality of life and psychological health in infertile couples: the moderating role of duration of infertility. Qual Life Res. 2018;27(4):945-54.

6. Cooper BC, Gerber JR, McGettrick AL, et al. Perceived infertilityrelated stress correlates with in vitro fertilization outcome. Fertil Steril. 2007:88:714-7.

7. Drosdzol A, Skrzypulec V. Quality of life and sexual functioning of Polish infertile couples. Eur J Contracept Reprod Health Care. 2008;13(3):271-8.

8. Keramat A, Masomi SZ, Mousavi SA, et al. Quality of life and its related factors in infertile couples. J Res Health Sci. 2014;14(1):57-63.

9. Coughlan C, Walters S, Ledger W, et al. A comparison of psychological stress among women with and without reproductive failure. Int J Gynecol Obstetr. 2014;124(2):143.

10. Maroufizadeh S, Ghaheri A, Omani SR. Factors associated with poor quality of life among Iranian infertile women undergoing IVF. Psychol Health Med. 2017;22(2):145-51.

11. Hassanin IMA, Abd-El-Raheem T, Shahin AY. Primary infertility and health-related quality of life in Upper Egypt. Int J Gynecol Obstetr. 2010;110:118-21.

12. Karabulut A, OzkanS ON. Predictors of fertility quality of life (FertiQoL) in infertile women: analysis of confounding factors. Eur J Obstet Gynecol Reprod Biol. 2013;170:193-7.

13. Chachamovich JR, Chachamovich E, Ezer H, et al. Investigating quality of life and health-related quality of life in infertility: a systematic review. J Psychosom Obst Gyn. 2010;31(2):101-10.

14. Rashidi B, Montazeri A, Ramezanzadeh F, et al. Health-related quality of life in infertile couples receiving IVF or ICSI treatment. BMC Health Serv Res. 2008;8:186

15. Hsu PY, Lin MW, Hwang JL, et al. The fertility quality of life (FertiQoL) questionnaire in Taiwanese infertile couples. Taiwan Assoc Obstetr Gynecol. 2013;52(2):204-9.

16. Boivin J, Takefman J, Braverman A. The fertility quality of life (FertiQoL) tool: development and general psychometric properties. Fertil Steril. 2011;96(2):409-15.
17. Kahyaoglu SH, Balkanli KP. Quality of life in women with infertility via the FertiQoL and the Hospital Anxiety and Depression Scales. Nurs Health Sci. 2015;17(1):84-9.

18. Namavar BJ, Mansouri M, Forouhari S, et al. Quality of life and its Influencing factors of couples referred to an infertility center in Shiraz. Iran Int J Fertil Steril. 2018;12(1):91.

19. Zimet GD, Dahlem NW, Zimet SG, et al. The multidimensional scale of perceived social support. J Person Assess. 1988;52(1):30-41.

20. Zung W. A rating instrument for anxiety disorders. Psychosomatics. 1971;12(6):371-9.

21. Zung wA self-rating depression scale. Arch Gen Psychiatry. 1965;12:63-70.

22. Karabulut A. Predictors of fertility quality of life (FertiQoL) in infertile women: analysis of confounding factors. Eur J Obstet Gynecol Reprod Biol. 2013;170(1):193-7.

23. Ying $L Y, W u L H$, Loke $A Y$. The experience of Chinese couples undergoing in vitro fertilization treatment: perception of the treatment process and partner support. PLoS One. 2015;10 (10).

24. Yang B, Zhang J, Qi Y, et al. Assessment on occurrences of depression and anxiety and associated risk factors in the infertile Chinese men. Am J Mens Health. 2017;11(3):767-74.

25. Chachamovich JR, Chachamovich E, Ezer H, et al. Investigating quality of life and health-related quality of life in infertility: a systematic review. J Psychosom Obstet Gynaecol. 2010;31(2):101-10.

26. Keramat A, Masoomi SZ, Mousavi SA, et al. Quality of life and its related factors in infertile couples. J Res Health Sci. 2014;14(1):57-63.

27. Maheshwari A, Stofberg L, Bhattacharya S. Effect of overweight and obesity on assisted reproductive technology - a systematic review. Hum Reprod Update. 2007;13(5):433-44.

28. Metwally $M$, Ong KJ, Ledger $W L$, et al. Does high body mass index increase the risk of miscarriage after spontaneous and assisted conception? A meta - analysis of the evidence. Fertil Steril. 2008;90(3):714-26.

29. Veleva Z, Tiitinen A, Vilska S, et al. High and low BMI increase the risk of miscarriage after IVF / ICSI and FET. Hum Reprod. 2008;23(4):878-84.

30. Parker $\mathrm{K}$, Wong $\mathrm{B}$, Link $\mathrm{B}$, et al. Does body mass index (BMI) affect IVF outcomes? Fertil Steril. 2011;96(3):124.

31. Matalliotakis I, Cakmak H, Sakkas D, et al. Impact of body mass index on IVF and ICSI outcome: a retrospective study. Reprod Biomed Online. 2008;16(6):778-83.

32. Nanette S, Esther Eisenberg JC, Trussell, , et al. Fertility-related quality of life from two RCT cohorts with infertility: unexplained infertility and polycystic ovary syndrome. Hum Reprod. 2016;31(10):2268-79.

33. Scott KM, Bruffaerts R, Simon GE, et al. Obesity and mental disorders in the general population: results from the world mental health surveys. Int J Obes (Lond). 2008;32(1):192-200.

34. Barry D, Pietrzak RH, Petry NM. Gender differences in associations between body mass index and DSM-IV mood and anxiety disorders: results from the National Epidemiologic Survey on Alcohol and Related Conditions. Ann Epidemiol. 2008;18(6):458-66.

35. Holley SR, Pasch LA, Bleil ME, et al. Prevalence and predictors of major depressive disorder for fertility treatment patients and their partners. Fertil Steril. 2015;103(5):1332-9.

36. Aarts JW, van Empel IW, Boivin J, et al. Relationship between quality of life and distress in infertility: a validation study of the utch FertiQoL. Hum Reprod. 2011;26(5):1112-8.

37. Kahyaoglu Sut H, Balkanli KP. Quality of life in women with infertility via the FertiQoL and the Hospital Anxiety and Depression Scales. Nurs Health Sci. 2014;17(1):84-99.

38. Wischmann T, Schilling $K$, Toth $B$, et al. Sexuality, self -esteem and partnership quality in infertile women and men. Geburtshilfe Frauenheilkd. 2014;74(8):759-63.

39. Lakatos E, Szigeti JF, Ujma PP, et al. Anxiety and depression among infertile women: a cross-sectional survey from Hungary. BMC Women's Health. 2017;17:48

40. Paulina G, Drozdowicz-Jastrzębska E, Barbara G, et al. Anxiety and depression in women undergoing infertility treatment. Ginekol Pol. 2017;88(2):109-12.

41. Martins MV, Peterson BD, Almeida VM, et al. Direct and indirect effects of perceived social support on women's infertility -related stress. Hum Reprod. 2011;26(8):2113-21. 
42. Yazdani F, Kazemi A, Fooladi MM, et al. The relations between marital quality, social support, social acceptance and coping strategies among the infertile Iranian couples. Eur J Obstet Gynecol Reprod Biol. 2016;200:58-62.

43. Cheng C-Y, Stevenson EL, Yang C-T, et al. Stress and quality of life for Taiwanese women who underwent infertility treatment. J Obstet Gynecol Neonatal Nurs. 2018;47(4):498-508.

44. Takaki J, Hibino Y. Family-related opinions and stressful situations associated with psychological distress in women undergoing infertility treatment. Int J Environ Res Public Health. 2014;11(9):9068-81.

\section{Publisher's Note}

Springer Nature remains neutral with regard to jurisdictional claims in published maps and institutional affiliations.
Ready to submit your research? Choose BMC and benefit from:

- fast, convenient online submission

- thorough peer review by experienced researchers in your field

- rapid publication on acceptance

- support for research data, including large and complex data types

- gold Open Access which fosters wider collaboration and increased citations

- maximum visibility for your research: over $100 \mathrm{M}$ website views per year

At BMC, research is always in progress.

Learn more biomedcentral.com/submissions 